\title{
Acute ST Elevation Myocardial Infarction by ECG Finding
}

National Cancer Institute

\section{Source}

National Cancer Institute. Acute ST Elevation Myocardial Infarction by ECG Finding. NCI

Thesaurus. Code C80384.

An electrocardiog raphic finding of an acute myocardial infarction which produces

characteristic elevations of the ST segment of the ECG. 